Portland State University

PDXScholar

Urban Studies and Planning Faculty

Nohad A. Toulan School of Urban Studies and

Publications and Presentations

Planning

$1-1-2010$

\title{
Manufactured Home Parks: NORCs Awaiting Discovery
}

Andrée Tremoulet

Portland State University, andree@commonworksconsulting.com

Follow this and additional works at: https://pdxscholar.library.pdx.edu/usp_fac

Part of the Urban Studies and Planning Commons

Let us know how access to this document benefits you.

\section{Citation Details}

Tremoulet, Andrée, "Manufactured Home Parks: NORCs Awaiting Discovery" (2010). Urban Studies and Planning Faculty Publications and Presentations. 70.

https://pdxscholar.library.pdx.edu/usp_fac/70

This Post-Print is brought to you for free and open access. It has been accepted for inclusion in Urban Studies and Planning Faculty Publications and Presentations by an authorized administrator of PDXScholar. Please contact us if we can make this document more accessible: pdxscholar@pdx.edu. 


\author{
Manufactured Home Parks: NORCs Awaiting Discovery \\ Andrée Tremoulet \\ Portland State University
}

Author Note

Andrée Tremoulet, Institute on Aging, Portland State University.

This research and manuscript preparation was supported in part by grants from the U.S. Department of Housing and Urban Development, Office of University Partnerships, the Oregon Housing and Community Services, and the Aging Matters Initiative at Portland State University. Correspondence concerning this article should be addressed to Andrée Tremoulet, Institute on Aging, Portland State University, P.O. Box 751, Portland, OR 97297-0751. E-mail: atrem@pdx.edu 


\begin{abstract}
This paper examines manufactured home parks as a type of naturally occurring retirement community and considers the potential for adding social service programs (NORC-SSP) to enable further aging in place. An analysis of six focus group interviews with 48 residents found that the physical and social environment promoted a sense of safety and community, and that this housing option was an intentional lifestyle choice. Risks included the possibility of bad management and park closure. Manufactured home parks were found to offer an attractive option for exploring a NORC-SSP model that builds on residents’ assets and community capacity.
\end{abstract}

Keywords: NORCs, manufactured housing, manufactured home parks, aging in place, housing for older adults 
The popular magazine Where to Retire describes manufactured homes as a "popular but controversial lifestyle option” for older persons (2010). Older persons, manufactured home fabricators, park owners, AARP, and the U.S. Department of Housing and Urban Development all have opinions about manufactured homes as housing for older persons. The gerontological literature, however, has not kept pace with the reality that nearly 13 million individuals age 50 or older reside in this housing type (Feldman, 2006). This paper examines the aging-in-place potential presented by this “popular but controversial” housing setting; specifically, it compares manufactured home parks to naturally occurring retirement communities (NORC) and considers the potential for social service programs in this unique form of neighborhood.

\section{NORCs and Manufactured Home Parks}

NORCs are geographically-defined areas with high concentrations of older adults (Hunt \& Gunter-Hunt, 1985; Hunt \& Ross, 1990; Marshall \& Hunt, 1999; Ivery, Akstein-Kahan \& Murphy, 2010). A principal distinction of NORCs is that they were not built as intentional retirement communities, but rather represent a place that evolved over time due to a combination of factors including older adults aging in place, the out-migration of younger households and the in-migration of older households (Carpenter et al., 2007; Ivery et al., 2010; Marshall \& Hunt, 1999).

The definition of NORC provided by the 2006 Older Americans Act Amendments (OAAA) reflects a range of applicable building types and geographies that include high rise towers (vertical NORCs) and neighborhoods (horizontal NORCs) in both urban and rural settings where a “critical mass of older individuals” lives (P. L. 109-365, Section 409). This “critical 
mass” has been defined in a variety of ways. It consists of a minimum concentration of residents (e.g., $25 \%, 40 \%, 50 \%$ or $65 \%$ of all residents or householders) of some minimum defined age (e.g., 50, 60, or 65) within a defined geographic location (Ivery et al., 2010; Lawler, 2001; Ormond, Black, Tilly \& Thomas, 2004).

Because manufactured home parks are not formally included in the NORC definition, this manuscript begins by considering whether and under what conditions they could be a NORC. Factors to consider include the percentage of older persons and whether the age status occurred by design or evolved over time. If some manufactured home parks are a type of NORC, then the research on NORCs is relevant to exploring the potential of manufactured home parks as an environment conducive to aging in place. Of particular interest is the potential applicability of the NORC Social Service Program (NORC-SSP) model to manufactured home parks.

For the purposes of this study, the key defining features of manufactured home parks are 1) housing stock primarily consisting of manufactured or mobile homes and 2) a tenure arrangement known as “divided asset ownership” (Hirsch and Rufolo, 1999). Under divided asset ownership, a landlord owns the land and common area improvements (e.g., clubhouse, water lines, streets), and individual homeowners own their homes ${ }^{1}$. A homeowner rents the space on which his or her house is located and pays for shared utility and common area maintenance costs. Divided asset ownership presents both potential benefits and vulnerabilities to the park residents, topics explored later in this paper.

Some manufactured home parks were planned as retirement communities, with facilities and services specifically intended for an older population and age-restricted leasing policies. These parks do not meet the "naturally occurring” component of a NORC. Other manufactured

\footnotetext{
${ }^{1}$ Some homes may be owned by the landlord or other investors and leased to residents. These residents pay rent for their homes and their spaces.
} 
home parks with high concentrations of older adults evolved into this age distribution of residents over time. Manufactured home parks with a high concentration of older adults straddle the definition of a NORC, with those that were intentionally constructed as retirement communities falling outside the boundaries, those that evolved into parks with a mixture of ages and a concentration of older residents falling inside, and those that were constructed as all-age parks and then converted into age 55 and older communities $(55+\text { parks })^{2}$ falling along either side, depending on whether a park still has some residents who are younger.

\section{Benefits of NORC-SSPs and Relevance to Manufactured Home Parks}

In some NORCs, coordinated social service programs were created with the goal of enabling residents to remain in their homes longer (NORC-SSPs). Partnerships formed among residents, health providers, social service providers, government agencies, philanthropies and housing managers to develop programs offering home and community-based services to NORC residents (Tilson, 1990). Evaluations of NORC-SSPs found that they resulted in numerous benefits to residents, including increased socialization, the reduction of social isolation (MacLaren, Landsberg \& Schwartz, 2007), and increased access to services, health promotion activities and crisis intervention.

Besides individual benefits, NORC-SSPs also were found to promote the formation of networks among residents and greater knowledge of and access to local resources, both elements of community capacity (Ivery et al., 2010). A high level of community capacity is characterized by strong bonds among residents, a sense of community and shared fate, knowledge of and access to outside resources, and the ability to solve problems and maintain or improve the

\footnotetext{
2 From 1988 to 1995, the Fair Housing Act required senior housing developments to have "significant facilities and services” that were designated for older adults. The Housing for Older Persons Act eliminated the significant facilities and services requirement. From 1995 onward, senior parks have been those that house at least one resident age 55 or older in at least $80 \%$ of the occupied units and that adhere to a policy that demonstrates the intent to house persons age $55+$.
} 
community (Chaskin, 2001). The structures for enabling community capacity can be formal (e.g., a neighborhood association, a housing co-op board) or informal (e.g., relationships among neighbors).

Conversely, MacLaren, Landsberg and Schwartz (2007) highlighted the importance of the leadership of housing co-op boards in fostering resident involvement in the design and implementation of social service programs in NORC-SSPs in New York State. The relationship between community capacity and service provision is reciprocal: service delivery can help create a higher level of community capacity, and existing community capacity can result in better service delivery. On an individual scale, a greater sense of self-efficacy and control over one’s environment has been associated with a greater sense of well-being.

Under what conditions might these findings apply to manufactured home parks? If a location is to be a setting for healthy aging in place, the residents who live there must see it as being desirable. It is an understatement to say that outsiders typically do not view manufactured home parks as good places to live. Often, the homes are viewed as being flimsy and the parks are viewed as being at best undesirable influences that depress adjacent property values. But such stereotypes can be misleading. Manufactured home parks can range from well-maintained communities with well-tended homes and active resident associations to a place with mud streets, a poorly-functioning waste disposal system and tainted water. Tremoulet (2010) examined the demographics of manufactured home park residents nationally and found that there is nearly as much variety among manufactured home park residents as those of traditional apartments or subdivisions of single-family site-built homes. Although it is true that, on average, manufactured housing residents have lower incomes than the population as a whole (median household income of $\$ 27,452$ for manufactured housing residents and $\$ 44,405$ for all 
households), in 2005 nearly one in 17 households who lived in manufactured housing (5.8\%) had annual incomes of $\$ 80,000$ or greater.

An analysis of data concerning parks and park residents in Oregon identified three broad clusters of residents: working class retirees, younger working class families and individuals, and families and individuals with very low-incomes (Tremoulet, 2010). The present study focuses on manufactured home parks that have a large proportion of residents who fall into the cluster of working class retirees. The qualitative research asks how manufactured home park residents themselves view their communities. It explores whether manufactured home parks represent housing of last resort, or whether and under what conditions they can represent a desirable housing choice for older adults, from the perspectives of the residents themselves.

\section{Research Questions}

This study explores the relevance of current findings regarding NORC residents and social service programs to manufactured home parks as a form of NORC. Using qualitative data collected from six focus group interviews with park residents in Oregon in 2007, this study answers the following research questions:

1. How do older residents of manufactured home parks view their homes and neighborhoods? Do they see their setting as a desirable location for aging in place? Why or why not?

2. What are the risks associated with living in a manufactured home park for older adults? Can these risks be mitigated?

3. How might the lessons learned about community capacity from the NORC-SSP model apply to manufactured home parks? 


\section{Design}

Focus groups were conducted in six manufactured home parks in Oregon during the summer of 2007 as part of a study to develop strategies to aid residents facing park closures. During the real estate boom of 2001-2007, approximately 2,800 households (approximately 6,000

individuals) were displaced in Oregon as a result of the closure of 69 manufactured home parks. The closures occurred because park owners either wanted to develop higher-yielding uses on the site themselves or had received an offer (sometimes unsolicited) from a developer to buy the park, close it, and do the same (Tremoulet, 2010). The focus group research was funded by the state housing agency, Oregon Housing and Community Services, which wanted to understand how to best address the rapid escalation in park closures.

While this article is primarily based upon information from the six focus groups, it is nested in a broader mixed-methods case study of the impacts of park closures on residents and how the Oregon state legislature responded to them (Tremoulet, 2010). This broader context informs the present study.

\section{Sample}

A theoretical sampling method that varied the size, location (rural, urban or suburban), state region, likelihood of closure, and resident characteristics (age, income level and race/ethnicity) was used to select the parks from which focus group participants were recruited. Table 1 presents a summary of the characteristics of the manufactured home parks included in this study. Each of the focus groups except for one was comprised of residents of a single manufactured home park; the other focus group consisted of residents of multiple 55+ parks located in the same area of the state. Four were designated as 55+ parks in the state registry, one was designated as a 
family park (all ages permitted) and one had no age designation. Research access to the parks was achieved by working through the state manufactured home park tenants association and a non-profit housing developer to recruit participants. As a result, it is likely that the sample is skewed toward parks that had active resident associations, and that parks with a lower level of social organization were under-represented.

Within the parks, a contact person, typically an officer of the resident association, recruited focus group participants. Although the contacts were asked to invite residents who represented the range of people who lived in their parks, it appeared that some invited those with whom they felt the most comfortable.

\section{Data Collection}

In general, the focus groups were conducted in the manufactured home parks. Three were conducted in the clubhouse, two were conducted in homes in the parks, and one was conducted at a nearby senior center because the park did not have a clubhouse. They ranged in size from two to fourteen members and were sixty to ninety minutes in duration. With the permission of the participants, the focus groups were audio-taped. Demographic data were collected from participants through a brief written questionnaire. The facilitator used a script but sometimes followed up with additional questions to probe the meaning of what participants said. In all of the focus groups, the question that evoked the most discussion was, "What was it that attracted you to buying a manufactured home and living in a manufactured home park?” Participants were eager to explain their choices and describe the benefits of living in a manufactured home park.

Conducting the focus groups within parks provided an opportunity for informal observations of each site. Field notes regarding the manufactured home parks, including observations of the 
homes, clubhouses, common areas, surrounding neighborhoods and resident interactions, constitute additional data included in this study.

\section{Data Analysis}

The focus group interviews were transcribed and the results coded thematically using a combination of pre-determined codes and ones that evolved during the coding process. The predetermined themes were based on the subject matter that Oregon Housing and Community Services had identified as being of importance to the agency, and included items such as "why I live in a manufactured home park," “where I turn for help,” and “my housing options if my park were to close.” Although the focus groups were not conducted with the intention of exploring the appropriateness of manufactured home parks as an environment for aging in place, this topic surfaced repeatedly. Specifically, the analysis resulted in unexpected findings regarding ways in which the physical and social environments of manufactured home supported aging in place. Since they are post hoc, the findings are exploratory, rather than conclusive, in nature. They do, however, carry the weight of veracity that comes from an unexpected discovery stemming from the life experiences of participants.

The preliminary results from the focus groups were reviewed by a committee that included officers from the statewide tenants association, two non-profit organizations that worked with park residents on a regular basis, and the state housing agency. This form of a "member check" is considered important for establishing the "truth value" of qualitative research (Strauss \& Corbin, 1990). The final results were presented in a report to Oregon Housing and Community Services and further disseminated by the author to focus group participants who had requested a copy. 


\section{Findings}

A total of 48 park residents participated in the focus groups. As Table 2 indicates, 79\% were age 60 or older. The households were small; 25\% of participants lived alone, and 44\% lived in two-person households. Less than 5\% had children age 18 or younger in their household. For half the residents, living in a manufactured home represented a relatively recent housing choice (e.g., they had lived in manufactured housing for six or fewer years), but nearly one in five (19\%) had lived there for 19 years or longer. Some had moved from another park to their present one; nearly two-thirds (62\%) had lived in their present park six years or less. Most (60\%) lived in a doublewide, and most (88\%) owned their homes outright.

The findings below begin with a description of the physical setting of manufactured home parks their surroundings. The section is based primarily on field observations. The next section addresses the second research question (i.e., manufactured home park as a setting for aging in place) by describing residents’ perceptions of the physical and social environment in which they lived. The third section examines an unexpected theme that arose during the focus groups, the level of community capacity within the parks. The reasons why participants moved to manufactured home parks are explored next, including precipitating events, financial considerations and whether they felt forced into this housing option. The findings conclude with a description of the residents' concerns about the vulnerabilities associated with this housing choice, which addresses the research question about risks of this model for aging in place.

\section{Manufactured Home Parks and Their Surroundings}

Manufactured home parks in Oregon function in many ways like gated communities for the aging working class. Often fences or hedges (sometimes required by local zoning ordinances) enclose them and set them apart from the surrounding area. They typically have a limited 
number of entrances and exits. Although none of the five parks visited for this study had a gatehouse or gatekeeper, homeowners near the entrances informally monitored the comings of goings of vehicles and pedestrians. Instead of being connected to the surrounding area through a grid of streets that pass through the park and into the larger neighborhood, the manufactured home parks had an internal, privately owned street system. Outsiders could not pass through the park en route to other destinations; the only people who entered the park were those who sought to be there.

Streets in the parks were narrow and not built to subdivision standards, as they were owned and maintained by the park owner. It was common to see a speed limit of 10 or 15 miles per hour prominently posted. The streets lacked sidewalks and curbs, but, given the lack of traffic and slow vehicular speeds, residents used the streets and shoulders as sidewalks. Community amenities included clubhouses (three parks), an old, in-ground swimming pool (one park), and large open areas or tree-shaded spaces that functioned as outdoor commons (several parks).

The homes themselves were situated on individual pieces of land called "spaces.” Like the spaces leased to individual vendors at a craft show, the spaces in manufactured home parks were not separate legal parcels. The size of the spaces (and the distance between homes) varied considerably from one park to the next. While park management maintained the common areas, individual park residents maintained their spaces and their homes. Many of the spaces had bright and abundant flower gardens, well-tended lawns, and a few tomato and other vegetable plants.

The areas surrounding the park varied considerably from one setting to the next. The new parks were in multi-family residential zones, while the older parks were built in industrial zones or in flood plains, and one park was in a transitional area, with light manufacturing uses adjacent and traditional site-built homes down the street. Some had been built on the outskirts of cities 
that had subsequently expanded to envelop the parks. Two suburban parks were surrounded by wooded land, but had highways and big box retail uses nearby. In both cases, residents spoke about the convenience of the park location. One person said, “All the amenities everyone needs is really right here within short walking distance.” Another said, “I love living here...the location is absolutely wonderful.”

\section{The Physical and Social Environment: Focus Group Findings}

Two inter-related themes about the physical and social environment of manufactured home parks surfaced in all the focus groups: personal safety and a sense of community. Participants used phrases such as "a good neighborhood," "like a family situation,” and "it’s very friendly" to describe how they felt about living in their parks. One person said, "We live very comfortably here, like if we were a community - better than any house and any apartment.”

Many focus group participants spoke about the sense of safety that they felt within their parks. One woman said, "I lived in a [site-built] home for 45 years in a very nice neighborhood. Would I have sat in the living room with my front door open and my back door open and unlocked? Not a bit, but I do it here.” A second participant said that she moved into a manufactured home park because it was affordable and felt secure and safe. The sense of safety enabled residents to stay physically active by walking, gardening, swimming (if the park had a pool) and participating in activities in the clubhouse.

Unlike traditional neighborhoods with fuzzy borders, where residents may have different perceptions of who belonged, park residents shared a common understanding of who was a neighbor. Someone either lived in the park or did not; that person either was a neighbor or not. For some residents, being a good neighbor implied a certain level of responsibility for others who lived in the park, as the following quote illustrates. 
There are 87 homes in this park, and I have lived in this neighborhood for 45 years. To date I haven't met all these people, but I have not met one that I don't like. We watch out for each other; we have our potlucks; we have our get-togethers.

The availability of safe outdoor areas where people could have casual exchanges with neighbors contributed to the sense of community. Even older, more physically vulnerable residents felt comfortable spending time outside, walking in the park, gardening or sitting on porches or in yards. One woman said, "I feel secure here. Even though it seems to be more and more ‘Lookey Loose’ coming in, I can walk my dog after dark. And I wouldn’t do that if I was in a stick-built.”

Participants described social activities, both formal and spontaneous, that played a major role in enhancing the quality of life. One park had no apparent scheduled social activities, but the swimming pool served as social hub during warm weather months. Some parks offered morning coffee in the clubhouse. Another park had a beautifully maintained clubhouse and an impressive list of clubs and activities organized by residents. The social committee at the latter park published a monthly newsletter with a calendar of events, which ranged from cookouts to card clubs. One woman said that she would strongly recommend that recent widows choose a park with a lively schedule of activities. Social activities in the park were convenient (a safe walk away) and provided an opportunity for interactions with familiar people.

Living in such close proximity to others could present challenges to one's sense of privacy, however. Residents developed strategies to deal with them, as the following discussion among several participants illustrates:

Resident 8: You are awful close to your neighbors, but, if you are a little careful, pick and choose kind of, you don't have to be buddy buddy with everybody.

Resident 4: I think that's one of the things that is very important, is to realize that you are not going to like everyone. You have 100 and some homes and you still want to be an individual. And like she said, you are really close to your neighbors, but you don't have to be in your 
neighbor's face. You can choose. If you are in an apartment, you walk out the door, you might walk right into somebody else...

Resident 5: This side [of my house], and you know who they are, but you don't really go to their house to have coffee.

Resident 4: You could get too close.

Interviewer: And what would be the downside of getting too close? What would that mean?

Resident 4: Nosiness, busy-ness, everyone knows your business. You don't want everybody to know your business. That's a downside. If you don't [usually] do this at 8:00, somebody is calling you [and asking,] "How come you are doing this at 8:00?” But the upside is that you do know certain people in the community where you live in. And God forbid you get sick or hurt, or something happens.

Resident 5: They are there if you need somebody.

Resident 4: Then there's people there and you can turn on that $100 \%$.

Resident 8: It is a friendship, but it doesn't have to be a close friendship to care about the person next door who fell ill and sent to the hospital, whose daughter gets sick or whose husband gets sick or whose wife gets sick. You know about it and it's nice to know that someone's there. Not that you are gonna call and say, “Get over here and help me.” But if you needed it, there's generally someone there and that's important.

Resident 4: That's a good feeling to know that there's someone there if I need somebody.

\section{Community Capacity}

Another unexpected finding from the focus groups was the degree to which residents had organized formal structures to respond to problems within their parks. A larger park had organized a Park Relations Committee to review and investigate issues or complaints from individual park residents and bring credible concerns to the park management as a group. A committee member explained, "When you go together as a group, it seems like it has a little more weight. But you gotta approach it nicely, in a good way, and work with it.” Residents from another park who had been unsuccessful in resolving a rent issue with the owner through dialogue banded together to hire a private attorney and split the cost. This approach resulted in 
the residents being successful in obtaining their objective, rent increases capped at the Consumer Price Index for existing residents. Another park was in the process of incorporating as a nonprofit organization to make a bid to purchase the park from the owner.

As noted previously, not all the organizing had occurred around solving a problem. Several parks had social committees that collected dues and planned community events and publicized them through a variety of means, including newsletters and websites.

In one case, organizing inside the park provided the springboard for successful political organizing citywide. After receiving a closure notice from the park owner, residents organized a citywide coalition to write letters to the editor, attend city council and other public meetings, and generally let elected officials and others know about their plight and that of other parks faced with closure in the area. In response, the city established a special committee comprised of a manufacture home park resident representative, a park owner representatives and city officials to work on the issue. As a result of this committee's work, the city adopted legislation that required park owners to either pay a higher level of compensation to displaced residents than required by state law or provide affordable housing in the new development.

\section{When and Why Older Adults Move to Manufactured Home Parks}

For many of the older adults in the focus groups, the move to a manufactured home park was precipitated by a major life event, such as divorce, the death of a spouse or a new or worsening mobility impairment that required that they live on one floor. One woman said, "I moved here in 1988 and at that moment in time, I had recently had a divorce. It was affordable, very secure, and the location was ideal.”

Others moved to a manufactured home park because they wanted to downsize from their existing traditional home with a yard to maintain. "We'd been in our home for 45 years, and we 
just had to downsize," one participant said. She added, "My husband's health went south and we couldn’t take care of it.” Some moved to be near family as they grew older. One couple, recently semi-retired, moved to a manufactured home park because they wanted to spend more time traveling. Moving to a manufactured home park both freed up economic resources for travel and resulted in a single-family detached home that required less maintenance.

Affordability and other financial considerations played a major role in why participants chose to live in a manufactured home park rather than in some other kind of housing. Participants said that a manufactured home had a lower purchase price and maintenance costs than conventional site-built housing. One said, "Living in [a mobile home park] is more affordable than a \$1,500 house payment.” Another said that renting their space allowed them to avoid paying as much as $\$ 1,000$ in taxes per year for land, even taking into account the taxes folded into their space rent. Several said that the monthly rent for their space in a manufactured home park was considerably less than that of an apartment in the area. For example, rent at one senior park in a major metropolitan area was $\$ 345$ per month, including garbage and water, which was considerably lower than market rents of $\$ 600$ - $\$ 750$ for a two-bedroom apartment at the time.

One participant explained his choice of moving to a manufactured home park as being a way to live comfortably with the smallest possible investment of his own resources. He said:

If you add up the land price and the land tax after you bought a $\$ 30,000$ piece of ground - it could be $\$ 40,000$, depending... The taxes on this place [the manufactured home park] are paid by the manager...the trash is picked up by him, the dumpster is empty and taken care of by him. We do have to pay an electric bill, phone bill and home things. You add those things up by the year, and you live in a place like that for 20 years, and you do save money. You wouldn't get that much out of a \$30,000 piece of ground that you got [owned] yourself. 
Although personal finances constrained the range of housing options that were within the means of park residents, most could have chosen to live in an apartment instead of a manufactured home park. But they did not make this choice. Participants consistently said that they found manufactured home park life far superior to living in an apartment. Older adults said that the principal benefits of living in a park instead of an apartment were a sense of personal safety and security, community, greater privacy, and the ability to continue to do the kinds of things (gardening, home improvement projects, etc.) that one can do in a site-built home that one owns, but at a smaller, more manageable scale. One woman said, "We sold our [site-built] home and we looked into an apartment and decided that he wouldn't have anything to do besides watch TV, and he needed something to do.”

Manufactured home park life clearly did not represent housing of last resort for these respondents. One woman said, "I want to be here forever." It represented a choice, not just of a housing form, but of a particular neighborhood type and community.

\section{Challenges of Manufactured Home Park Living}

Thus far, this paper has focused on the positive aspects of manufactured home parks and how they might provide a physical and social environment conducive to aging in place. But focus group results indicated that manufactured home park living is not without its down sides. The two principal concerns that arose during the focus groups were 1) vulnerability to poor quality management and 2) vulnerability to closure by the owner of the manufactured home park.

Some of the problems with park management resulted from inadequate maintenance, such as poor drainage, potholes, trees in need of trimming and a lack of water for maintaining the common areas. Other problems arose from management failing to enforce its own rules, as in the case of some residents being allowed to keep too many large dogs. Some problems were 
serious in nature, as in the case of the criminal activity that developed over time in one park when management failed to undertake adequate background checks on new residents. Participants described a local “meth house,” alleged prostitution, and at least one raid that resulted from resident complaints directly to the police.

Park residents sometimes felt that they did not have enough leverage to get the manager or owner to do what was needed to resolve the problem. One participant described his sense of vulnerability to poor quality park management as follows:

Right now our management is very good, but in the past it not always has been on occasion. There has been a recent time a feeling of hopelessness over the management situation because we're not really sure where to turn to get some help fixing that issue. It was, for a while, a park-wide issue, and I don't think anyone knew which way to turn. And we don't have contact with the owner.

While state landlord tenant laws are intended in part to protect tenants’ interests, focus group participants pointed out that the only way to force compliance with these laws in Oregon is to sue the owner in civil court. One resident said, "There's nothing that covers us or protects us, you know. With the state rules, the owner knows that he can do whatever we wants...There’s no back-up.” Participants believed that property owners had the preponderance of power when landlord-tenant problems arose.

A second area of vulnerability for residents stemmed from the possibility that the park owner might close the park. The threat was particularly tangible to focus group participants because of media stories about the rising incidence of park closures. The thought of a closure was frightening because there were so few options for where to move one's home, particularly for older homes. One woman said, “There’s no place that would take us.” Many older homes could not be moved because they were too fragile. Residents were acutely aware of the impact 
of park closures on older residents. One resident said, “For the elderly, most of them, they can't move. It's infeasible for them. They are on fixed incomes.”

As Table 1 indicates, park owners had issued closure notices at two of the parks included in this study, but had postponed further action. More than half of the long-term residents in one park moved out when they received the notice. “A lot of older people got scared out," a focus group participant said. When asked where they went, she said, "Wherever they could."

Whether or not the benefits of park living outweighed the vulnerabilities that residents felt appeared to be an individual decision. The focus groups were conducted at the height in publicity about park closures. In the same park, some focus group participants said that they would still choose to move to their park if they had the opportunity to enter a time machine and remake that choice all over again. Others were less certain. Some said that the sense of vulnerability that they felt cost them too much, and they indicated that they would not make the same choice.

\section{Discussion}

Living in a manufactured home park for most focus group participants represented more than the selection of a housing option; it represented a lifestyle choice. Although choices were constrained by financial resources, most could have chosen to live in an apartment. What is it about manufactured home parks that make them attractive places to live as one begins to age and find the environmental press of maintaining a larger single-family site-built home too much?

Manufactured homes are smaller, have one-story interiors (most have an entry above grade) and involve a less expansive yard to maintain than a single-family home. Yet they provide physical separation not offered by apartments. Furthermore, the resident owns the home; he or 
she can personalize it (e.g., remodel, repair and decorate it) in ways that might not be permitted in apartments. Park management does not inspect manufactured home interiors. Owning one's manufactured home enables self-expression and freedom from unwanted intrusion. But privacy and personal freedom represent only one part of the equation.

The other side of the equation consists of access to community and an associated sense of personal safety. Parks appear to offer occupants the ability to choose a balance between privacy and community that suits one's needs. Parks seem to make community available if one wants it, through familiarity with neighbors, the presence of a safe and monitored environment for casual interactions, and the availability of planned social activities. Privacy within one's home is available as well.

In a sense, manufactured home parks may offer some of the advantages of a vertical NORC combined with those of a horizontal NORC. Vertical NORCs—typically a single high-rise or closely related dwellings_—provide access to joint community space, shared management and (in many cases) a network of relationships among residents who share the same residence. In contrast, the environment of horizontal NORCs (neighborhoods) requires a higher level of independence and, in the case of a neighborhood of single-family homes, may provide opportunities for more self-expression.

These preliminary findings suggest that some manufactured home park settings may offer a more expansive and flexible continuum between privacy and community than either traditional neighborhoods with site-built single-family detached homes or apartment complexes. Longitudinal research is needed to determine if this setting enables residents to interact with their environment (both physical and social) in differing ways as their abilities and needs change with age. 
The physical characteristics of a manufactured home park-its separation from the surrounding community, its internal focus, the pattern of single-family homes within a community circumscribed by clear boundaries, the presence of one or more shared spaces that serve as focal points, and the availability of homes and yards that can be personalized—affect both social interactions within the park and how residents interact with their environment. By providing a sense of safety, spaces to personalize, interesting destinations and places to walk, and the option of having pets, manufactured home parks have the potential to encourage active living.

Both the physical setting and the self-selection of residents appeared to create an environment conducive to forming bonds among residents. Considerable empirical evidence substantiates that social networks and social support systems help protect against illness, enhance coping skills and improve the outcomes of bouts of illness among older adults generally. Although this study did not formally analyze the extent or depth of informal social support systems in the parks, it was clear that the focus group participants watched out for each other and were willing to lend a hand during hard times. An area for future research would be to analyze the social support networks that exist in manufactured home park settings, and to compare these networks to those in NORCs and in other settings with a high concentration of older adults.

Manufactured home park living is not without substantial risks, however. The exposure to poor quality management and park closure both stem from a single underlying cause: divided asset ownership. When manufactured homes were truly mobile, homeowners could move their homes to new locations if they were willing to incur a reasonable cost. But with the onset of doublewide and larger homes in the late 1960s (Hart, Rhodes and Morgan, 2002), it became 
more expensive to move a home. The cost to move a doublewide to a new site in Oregon in 2007 could easily exceed \$25,000 (Tremoulet, 2010). In many cases, homeowners settle in and build carports, porches and outbuildings to supplement the living space provided by their homes. If they move, residents lose their investment in these additional improvements and their garden and other landscaping. Many homes were simply too old to be moved without falling apart. Even if the home were well maintained, the options for finding a space for an older home were likely to be limited because of a practice by park owners of only allowing newer homes—such as those manufactured in the last ten years — to be moved to their parks. Furthermore, when parks close, residents lose not only their location, their home and their largest single investment, but also their community and all that is familiar.

A promising direction is the promulgation of new ownership options that give manufactured home park residents greater security of tenure. To date, there are three primary models: the formation of resident-owned communities or cooperatives, purchase by a housing authority that agrees to make the park permanently affordable, and purchase by a non-profit organization that agrees to do the same.

New Hampshire leads the nation in resident-owned communities, where more than $20 \%$ of all manufactured home parks in the state are owned by resident co-operatives. In 2008, leaders from the New Hampshire Community Loan Fund joined with three national non-profits, the Corporation for Enterprise Development (CFED), NCB Capital Impact, and NeighborWorks America, to create ROC USA, a platform for promulgating the resident-owned community model nationally (ROC USA, 2010).

A second promising direction is the adoption of stronger resident protections within state landlord-tenant laws to provide residents with greater leverage in dealing with park owners who 
do not adequately maintain their parks. In contrast to other states, Washington’s Attorney General investigates claims and, if the complaint has merit and negotiations fail, imposes fines if problems are not remedied and compliance achieved (Washington State Office of the Attorney General, 2010).

A final area to explore is the relevance of the NORC-SSP model to manufactured home parks. The benefits of service delivery in NORC-SSPs have been found to be amplified in settings with strong community capacity, characterized by strong bonds among residents, a sense of community and shared fate, the ability to address problems as a community, and knowledge of and access to outside resources. Manufactured home parks appear to embody the first three of these characteristics; however, it is not known whether this setting has any effect on the density or strength of links with external sources of assistance. To some degree, the provision of services may provide the missing link — the connection to outside help—-that would enable park residents to age in place for a more extended period of time. It is possible that, as in the case of NORC-SSPs in traditional settings, coordinated service delivery may enhance community capacity, and community capacity many enhance the effectiveness of service delivery.

Although the NORC-SSP model appears to be relevant to manufactured home parks, there are several issues to consider. One is the degree of openness of park residents to outsiders. Many older residents live in parks because they want to be independent; some may not think well of “service provision.” The importance of working with and through existing resident associations or informal leadership structures to gain the trust of residents cannot be underestimated. Language is also important; terms other than "services," which may connote neediness, dependency and government handouts, should be explored. 
A second issue to consider stems from divided asset ownership: the willingness of park owners to allow services in their park, especially if services are provided in group settings outside individual homes. Research is needed to understand the decision-making calculus that the park owner might work through in considering whether to facilitate the promulgation of a NORC-SSP model in her or his park. On one hand, the landlord might perceive service providers as tenant advocates who would make demands or create trouble. On the other hand, the landlord might welcome services that allow aging tenants to continue living in the park and paying rent. For example, the owner of a park in Eugene, Oregon, was exploring the feasibility of building two adult foster homes onsite so that residents who were no longer able to remain in their homes had the option of remaining in the community and moving to a setting that provided formal assistance.

Manufactured home parks represent a promising location for demonstration projects to test how to apply lessons from NORC-SSPs to this new setting. The easiest place to start would be with larger parks that have a high concentration of older adults (for economies of scale in service delivery), offer security of tenure and have a well-organized resident association. A larger 55+ resident-owned community that has a clubhouse with space for both community activities and private appointments might well be a prime location for such a demonstration project.

\section{Conclusion}

As states and communities plan to accommodate the rising tide of aging Baby Boomers in an era of scarce resources, strategies that enable residents to age in place with minimal public investment will become increasingly important. At present, manufactured home parks represent a largely overlooked resource. Older residents with modest incomes who live in manufactured 
home parks can bring a lot to the table: their homes, their ability to take care of each other, their ability to organize and take an active role in planning the menu of assistance that works in their community. Manufactured home parks offer an attractive option for exploring a NORC-SSP model to promote aging in place that builds on resident assets and community capacity and minimizes public investment. They may be a particularly effective choice for rural or lessdensely developed areas, where serving a geographically dispersed population drives up costs.

One person’s simple home may be another person’s castle. Manufactured home parks deserve a higher level of research and policy attention as a place where older adults with modest incomes age in place. 


\section{References}

Callanan, James J., \& Lansperry, Susan. (1997). Can we tap the power of NORCs? Perspectives on Aging, 26 (1), 13-20.

Carpenter, Brian D., Edwards, Dorothy F., Pickard, Joseph G., Palmer, Janice L., Stark, Susan, Neufeld, Peggy S., Morrow-Howell, N., Perkinson, Margaret A., \& Morris, John C. (2007). Anticipating relocation: Concerns about moving among NORC residents. In Phillip McCallion (Ed.), Housing for the elderly (pp. 165-184). New York: Haworth Press.

Chaskin, Robert J. (2001). Building community capacity: A definitional framework and case studies from a comprehensive community initiative. Urban Affairs Review, 36, 291322. doi:10.1177/10780870122184876.

Colello, Kirsten J. (2007). CRS Report for Congress: Supportive Services Programs to Naturally Occurring Retirement Communities (Congressional Research Service Order Code No. RL34289). Washington, DC: Congressional Research Service.

Feldman, K. (2006). Latest trends in manufactured housing. Where to Retire, 15 (1), 66-70+.

Glass, Anne P. (2009). Aging in a community of mutual support: the emergence of an elder intentional cohousing community in the United States. Journal of Housing for the Elderly, 23, 283—303. doi: 10.1080/02763890903326970.

Gozonsky, Moses. (1991). A look at naturally occurring retirement communities. Perspectives on Aging, 20(4\&5), 33-34.

Hart, J. F., Rhodes, M. J., \& Morgan, J. T. (2002). The unknown world of the mobile home. Baltimore: The Johns Hopkins University Press.

Hirsch, W. Z. \& Rufolo, A. M. (1999). The regulation of immobile housing assets under divided asset ownership. International Review of Land and Economics, 19(3), 383-397.

Hunt, Michael E. \& Gunter-Hunt, G. (1985). Naturally occurring retirement communities. Journal of Housing for the Elderly, 3, 3-21.

Hunt, Michael E., \& Ross, Leonard E. (1990). Naturally occurring retirement communities: A multiattribute examination of desirability factors. The Gerontologist, 30, 667-674. Retrieved from http://ejournals.ebsco.com/

Ivery, Jan M., Akstein-Kahan, Deborah, \& Murphy, Kathleen C. (2010). NORC supportive services model and community capacity. Journal of Gerontological Social Work, 53, 21—42. doi: 1080/01634370903412194. 
Lawler, K. (2001). Aging in place: Coordinating housing and health care provision for America's growing elderly population. Cambridge, MA: Joint Center for Housing Studies.

Marshall, Linda M., \& Hunt, Michael E. (1999). Rural naturally occurring retirement communities: A community assessment procedure. Journal of Housing for the Elderly, 13 (1), 19—34. doi: 10.1300/J081v13n01_03.

MacLaren, Catherine, Landsberg, Gerald, \& Schwartz, Harry. (2007). History, accomplishments, issues and prospects of supportive services programs in Naturally Occurring Retirement Communities in New York State: Lessons learned. In Phillip McCallion (Ed.), Housing for the elderly: Policy and practice issues (pp. 127-144). New York: Haworth Press.

Ormand, B., Black, K.J., Tilly, J., \& Thomas, S. (2004). Supportive Services Programs in Naturally Occurring Retirement Communities. Washington, DC: Urban Institute.

ROC USA. (2010). Background. Retrieved from http://www.rocusa.org/aboutus/background/default.aspx

Strauss, Anselm L. \& Corbin, Juliet M. (1990). Basics of qualitative research: grounded theory procedures and techniques. Newbury Park, CA: Sage Publications.

Tilson, D.(1990). Aging in place. Glenview, IL: Scott Forsemann \& Co.

Tremoulet, A. (2010). Policy responses to the closure of manufactured home parks in Oregon (Doctoral dissertation). Retrieved from ProQuest Dissertations \& Theses: Full Text. (Publication No. AAT 3389414).

Washington State Office of the Attorney General. (2010). Manufactured housing dispute resolution program. Retrieved from http://www.atg.wa.gov/MHDR.aspx

Where to Retire (2010). Should you retire to a manufactured home? Where to Retire Magazine. Retrieved from http://wheretoretire.com/reports.cfm 